\title{
Transatlantica
}

Revue d'études américaines. American Studies Journal

\section{Quelques sites pour poursuivre la réflexion autour des événements du 11 septembre}

\section{(2) OpenEdition}

Journals

Édition électronique

URL : http://journals.openedition.org/transatlantica/470

DOI : $10.4000 /$ transatlantica.470

ISSN : $1765-2766$

Éditeur

AFEA

Référence électronique

"Quelques sites pour poursuivre la réflexion autour des événements du 11 septembre », Transatlantica [En ligne], 1 | 2001, mis en ligne le 23 mars 2006, consulté le 29 avril 2021. URL : http://

journals.openedition.org/transatlantica/470 ; DOI : https://doi.org/10.4000/transatlantica.470

Ce document a été généré automatiquement le 29 avril 2021.

\section{(c)}

Transatlantica - Revue d'études américaines est mis à disposition selon les termes de la licence Creative Commons Attribution - Pas d'Utilisation Commerciale - Pas de Modification 4.0 International. 


\section{Quelques sites pour poursuivre la réflexion autour des événements du 11 septembre}

1 Nous proposons ici quelques liens vers des pages « universitaires» qui permettent de prolonger la réflexion américaniste sur les événements du 11 septembre.

Pages de la Library of Congress : http://150.156.112.3

2 Il s'agit d'un projet archivistique conjoint LC, webArchivist.org et Pew Internet \& American Life Project. Son objectif est, comme l'archive web dédiée aux élections de 2000, d'archiver des pages web rendant compte de l'impact des événements du 11 septembre et de conserver ainsi des documents électroniques qui souvent disparaissent rapidement des serveurs.

WebArchivist.org est un groupe de recherches sur les méthodes d'analyse du web dirigé par Steven M. Schneider, politiste à SUNY Institute of Technology at Utica/Rome, et Kirsten A. Foot, spécialiste de communication à l'Université de Washington.

The Pew Internet \& American Life Project quant à lui s'intéresse à l'impact d'internet sur les enfants, les familles et plus largement les groupes et le travail.

Pages de l'Organization of American Historians (OAH)Assessing September 11

Historians Richard H. Kohn and Edward T. Linenthal share their thoughts on the events of September 11.

http://www.oah.org/pubs/nl/2001nov/kohn.html?etmnnl02

7 http://www.oah.org/pubs/nl/2001nov/linenthal.html?etmnnl03

Terrorists Target History

8 John Carlin addresses the importance of maintaining records in the wake of September 11.

9 http://www.oah.org/pubs/nl/2001nov/carlin.html?etmnnl05

National Security Archive Online Readers on Terrorism, Intelligence, and the Next War http://www.gwu.edu/ nsarchiv/NSAEBB/sept11/ 
Documents et sources sur les événements compilés par un documentaliste (Gary Price, MLIS Librarian \& Information Consultant Washington DC)

11 http://www.freepint.com/gary/91101.html 